\title{
Predictors and Typical Clinical Findings of Refractory Epilepsy
}

\author{
E. Viteva* \\ Department of Neurology, University of Medicine, Plovdiv, Bulgaria \\ *Corresponding author: eiviteva@abv.bg
}

Received January 14, 2014; Revised January 22, 2014; Accepted February 07, 2014

\begin{abstract}
Purpose: Our purpose was to identify the predictors of refractory epilepsy (RE) and the typical clinical findings in Bulgarian patients with RE. Patients and Methods: We studied 70 adult patients with refractory epilepsy and 70 patients with pharmaco sensitive epilepsy. The Liverpool Seizure Severity Scale was completed by 84.29\% of the patients with RE. Results: The typical clinical findings and significant predictors of RE on univariate analysis were: high initial seizure frequency $(\mathrm{OR}=2.45)$, heredity for epilepsy $(\mathrm{OR}=8.90)$, febrile seizures $(\mathrm{OR}=$ $4.50)$, partial epilepsy $(\mathrm{OR}=5.98)$, low or lacking seizure reduction with the first $\mathrm{AED}(\mathrm{OR}=44.0)$, clusters of seizures and/or epileptic status in the disease course $(\mathrm{OR}=16.5)$, childhood onset $(\mathrm{OR}=8.0)$, great number of ineffective antiepileptic drugs ( $\mathrm{AED})-\mathrm{OR}=232.88$, poly therapy $(\mathrm{OR}=61.0)$. On multivariate analysis significant predictors of RE were poly therapy ( $\mathrm{B}=4.86)$, childhood onset $(\mathrm{B}=2.79)$, and great number $(>4)$ of ineffective AED $(B=5.44)$. Frequent clinical findings were: moderate seizure severity, high seizure frequency despite the prescribed treatment, polymorphic seizures. Conclusion: The most significant predictors of RE are: great number of ineffective AED, treatment with poly therapy, and early disease onset. This conclusion may be useful for a timely identification of patients with epilepsy who are likely to be refractory to medical therapy.
\end{abstract}

Keywords: predictor, refractory, epilepsy, clinical finding, typical

Cite This Article: E. Viteva, "Predictors and Typical Clinical Findings of Refractory Epilepsy." American Journal of Clinical Medicine Research, vol. 2, no. 1 (2014): 26-31. doi: 10.12691/ajcmr-2-1-7.

\section{Introduction}

Despite the various modern ways of treatment, in 20$35 \%$ of the cases with epilepsy seizures are uncontrolled and the disease is accepted as refractory. The knowledge about refractory epilepsy (RE) predictors is very important for its early recognition and adequate treatment. In literature sources the following clinical findings have been most frequently mentioned as typical of RE: 1. A determined heredity for epilepsy [1]; 2. A symptomatic and cryptogenic etiology of epilepsy [2]; 3. Complex febrile seizures and a febrile epileptic status [1,3,4,5,6]; 4. An early onset of epileptic seizures (especially before 1 year of age), a high initial seizure frequency and duration, clusters of seizures and an epileptic status, a long period between the first seizure and the beginning of treatment with antiepileptic drugs (AED) [2,3,4,7-21]; 5. Infantile spasms, atonic seizures in the disease course and according to some investigators-generalized tonic and simple partial seizures [16,19,22]; 6. Focal neurological signs which are usually associated with a brain lesion $[9,22] ;$ 7. A poor answer to the first AED $[2,10,13,15,19,23,24,25]$. The greater duration of the disease usually correlates with a lower probability for a satisfactory clinical effect $[2,8,10,13,15,23,26]$.

In Bulgaria detailed studies on the predictors and typical clinical findings of the RE have never been performed.
Purpose: Our purpose was to identify the predictors of refractory epilepsy (RE) and the typical clinical findings in Bulgarian patients with RE.

\section{Patients and Methods}

The study was performed with the participation of a representative selection of patients with epilepsy who attended the Clinic of Neurology at the University Hospital in Plovdiv, Bulgaria for a regular examination or in cases of unsatisfactory seizure control or adverse events from treatment.

All study procedures were performed after the approval of the Local Ethics Commission at the University of Medicine, Plovdiv. Every patient was introduced to the study design and signed an informed consent form before participation in the study procedures.

The study included 94 patients with RE and 70 patients with pharmaco sensitive epilepsy (PSE). Epilepsy was accepted as refractory in cases in which adequate seizure control with at least 2 potentially effective AED prescribed as mono or poly therapy in maximally tolerated doses had not been achieved. The following inclusion criteria for both groups were used: a signed informed consent form; age between 18 and 65 years; a diagnosis of $\mathrm{RE}$ or PSE; lack of cognitive impairment based on Evaluation rapide des fonctions cognitives (ERFC; Gil and Toullat, 1986) with a score $<47$ in patients up to 60 
years of age and primary education or $<46$ in patients between 60 and 65 years of age and less than a primary education or illiteracy; lack of progressive somatic or neurological disease; lack of a simple or complex partial seizure in the last 4 hours; and lack of generalized tonicclonic seizures in the last 24 hours.

From the participants with RE 70 patients were selected for comparison of the clinical findings with 70 outpatients with PSE; both groups were similar with respect to age and gender. The presence of a significant difference between both groups was studied regarding the following clinical findings: age of epilepsy onset, duration of epilepsy, heredity, type of seizures, trigger factors, febrile seizures, initial seizure frequency, seizure clusters and/or epileptic status, recent seizure frequency, seizure severity during the last month, type of epilepsy, etiology of epilepsy, recent therapy with AED, seizure reduction with the first AED, number of ineffective AED applied in the disease course, focal neurologic signs. The data were collected by a trained neurologist (specialized in epilepsy) through a purposeful interview, an examination of the patients' medical documentation and seizure diaries, and a neurological examination of the study participants.

The Liverpool Seizure Severity Scale (LSSS; Baker, 1993) was completed by 59 patients with RE (84.29\%) who had had seizures with different severity during the last month. The rest of the patients with RE and the participants with PSE did not complete this scale because they had been without seizures in this period. The lack of mental retardation was confirmed based on a psychiatric consultation.

The collected primary information was checked, encoded, and entered into a computer database for statistical analysis. Data were processed using STATA Version 10 (Stata Corp., College Station, TX, U.S.A.) and SPSS (Statistical Package for the Social Sciences), version 14.0 (SPSS Inc., Chicago, IL, U.S.A.). Results for quantitative variables were expressed as mean \pm SE (standard error) and results for qualitative variables as percentages \pm SE. Patients with RE and PSE were compared with respect to their clinical findings by means of $\chi^{2}$-Test, Z-Test, and u-Test. Pearson's correlation coefficient was used to determine correlations between the above mentioned characteristics. Univariate analysis was performed to find the association between every clinical finding and the diagnosis RE [odds ratio (OR) and confidence interval (CI)]. The complex influence of the significant clinical findings was determined by means of multivariate logistic regression analysis [regression coefficient (B)]. The level of significance was set at $\mathrm{P}<$ 0.05 .

\section{Results}

Overall, 27 (28.72\%) of the participants with RE were men; the remaining 67 participants $(71.28 \%)$ were women. Their mean age was $41.72 \pm 1.08$ years. Most patients (76.6\%) were between 30 and 60 years of age. For the purpose of comparison, 70 patients with RE were selected - 25 (35.71\%) men and 45 (64.29\%) women. Their mean age was $37.97 \pm 1.30$ years, and they were compared with 70 patients with PSE - 34 (48.57\%) men and 36 (51.43\%) women with a mean age of $36.70 \pm 1.49$ years. There was no significant difference between both groups regarding their gender $\left(\mathrm{P}>0.05, \chi^{2}=2.37\right)$ and age $(\mathrm{P}>0.05, \mathrm{u}=$ 0.64).

The mean age onset of epilepsy was $13.09 \pm 1.27$ years for the patients with RE and $26.87 \pm 1.87$ years for the patients with PSE $(\mathrm{u}=6.29, \mathrm{Pu}<0.001)$. The mean duration of epilepsy was $25.07 \pm 1.32$ years for the participants with RE and $10.66 \pm 0.76$ years for those with PSE ( $u=9.48, \mathrm{Pu}<0.001$ ). The clinical findings of the patients with RE and PSE are presented in Table 1.

The most frequent trigger seizures factors were: emotional stress (53.58\%), menstruation (7.14\%), fever (7.14\%), photostimulation (7.14), and insomnia (3.57\%).

The most frequent causes for the symptomatic etiology in the patients with RE were: traumatic injury - in 11 patients (39.29\%), inflammation - in 5 (17.86\%), perinatal pathology - in 4 (14.29\%), tumor - in 3 (10.71\%), and hippocampal sclerosis - in $3(10.71 \%)$ paticipants.

The mean number of ineffective AED prescribed for the patients with RE was $5.73 \pm 0.19$, and for those with PSE - $0.49 \pm 0.08$. The difference between both groups was significant regarding this variable $\mathrm{Pu}<0.001 \mathrm{(u}=25.68, \mathrm{r}$ $=-0.91)$.

Variables found to be significantly associated with RE on univariate analysis were high initial seizure frequency $(\mathrm{OR}=2.45,95 \% \mathrm{CI}=1.23-4.87)$, heredity for epilepsy $(\mathrm{OR}=8.90,95 \%=1.08-73.21)$, febrile seizures $(\mathrm{OR}=$ 4.50, 95\% CI $=1.57-12.93)$, partial epilepsy (OR $=5.98$, $95 \% \mathrm{CI}=2.86-12.48)$, low or lacking seizure reduction with the first $\mathrm{AED}(\mathrm{OR}=44.0,95 \% \mathrm{CI}=12.3-157.36)$, clusters of seizures and/or epileptic status in the disease course $(\mathrm{OR}=16.5,95 \% \mathrm{CI}=5.42-50.2)$, childhood onset (earlier than 14 years) - OR $=8.0,3.73-17.14$, great number of ineffective antiepileptic drugs (OR $=232.88$, $95 \%$ CI $=29.94-1811.54)$, poly therapy $(\mathrm{OR}=61.0,95 \%$ $\mathrm{CI}=21.38-174.07)$. Significant variables were considered for multivariate analysis. The three variables proven to be significant on multivariate analysis were: poly therapy (B $=4.86 \pm 1.17, \mathrm{P}=0.001)$, childhood epilepsy onset $(\mathrm{B}=$ $2.79 \pm 1.13, P=0.01)$, and great number $(>4)$ of ineffective AED $(\mathrm{B}=5.44 \pm 1.49, \mathrm{P}=0.001)$. On the ground of these three factors a model for RE risk assessment was formed. The predictive value of this model was $88 \%\left(P=0.001, \chi^{2}=149.45\right)$. The variable great number of ineffective AED had the most significant influence in this model.

No significant association between the variables etiology, recent seizure frequency, last month seizure severity, seizure type, trigger factors, focal neurological signs, and RE was demonstrated ( $\mathrm{P}>0.05)$.

\section{Discussion}

The purpose of our study was to identify the predictors of RE and the typical clinical findings in Bulgarian patients with RE.

A significantly earlier age onset was found in the patients with RE (about 13 years of age). Our results support the conclusion of many scientists about the significant association of the childhood onset of epilepsy with its treatment resistance [2,3,4,6$12,19,21,22,23,27,28,29]$. This variable has been accepted as one of the most significant predictors of intractability as well. 
Table 1. Clinical findings of the patients with RE and PSE

\begin{tabular}{|c|c|c|c|c|c|c|c|}
\hline \multirow{2}{*}{ Clinical finding } & \multicolumn{2}{|r|}{$\mathbf{R E}$} & \multicolumn{2}{|r|}{ PSE } & \multirow{2}{*}{$\chi^{2} Z$} & \multirow{2}{*}{$\mathbf{P}$} & \multirow{2}{*}{$\mathbf{r}$} \\
\hline & $\mathbf{N}$ & $\mathrm{P} \% \pm \mathrm{SE}$ & $\mathbf{N}$ & $\mathrm{P} \% \pm \mathrm{SE}$ & & & \\
\hline $\begin{array}{l}\text { Heredity } \\
\text {-no } \\
\text {-yes }\end{array}$ & $\begin{array}{c}62 \\
8\end{array}$ & $\begin{array}{l}88.57 \pm 3.80 \\
11.43 \pm 3.80\end{array}$ & $\begin{array}{c}69 \\
1\end{array}$ & $\begin{array}{c}98.57 \pm 1.42 \\
1.43 \pm-\end{array}$ & $\chi^{2}=5.82$ & $<0.05$ & +0.20 \\
\hline $\begin{array}{l}\text { Type of seizures } \\
\text {-partial } \\
\text {-generalized } \\
\text {-polymorphic }\end{array}$ & $\begin{array}{l}17 \\
16 \\
37\end{array}$ & $\begin{array}{l}24.29 \pm 5.13 \\
22.86 \pm 5.03 \\
52.86 \pm 5.97\end{array}$ & $\begin{array}{l}24 \\
46 \\
-\end{array}$ & $\begin{array}{l}34.29 \pm 5.67 \\
65.71 \pm 5.67 \\
-\end{array}$ & $\chi^{2}=52.71$ & $<0.001$ & +0.42 \\
\hline $\begin{array}{l}\text { Trigger factors } \\
\text {-no } \\
\text {-yes }\end{array}$ & $\begin{array}{l}48 \\
22\end{array}$ & $\begin{array}{l}68.57 \pm 5.55 \\
31.43 \pm 5.55\end{array}$ & $\begin{array}{l}56 \\
14\end{array}$ & $\begin{array}{l}80.00 \pm 4.78 \\
20.00 \pm 4.78\end{array}$ & $\chi^{2}=2.39$ & $>0.05$ & - \\
\hline $\begin{array}{l}\text { Febrile seizures } \\
\text {-no } \\
\text {-yes }\end{array}$ & $\begin{array}{l}52 \\
18\end{array}$ & $\begin{array}{l}74.29 \pm 5.22 \\
25.71 \pm 5.22\end{array}$ & $\begin{array}{c}65 \\
5\end{array}$ & $\begin{array}{c}92.86 \pm 3.08 \\
7.14 \pm 3.08\end{array}$ & $\chi^{2}=8.79$ & $<0.01$ & -0.25 \\
\hline $\begin{array}{l}\text { Initial seizure frequency } \\
-1 / \text { several years } \\
-1-11 \text { seizures/year } \\
-1-3 \text { seizures/month } \\
-1-6 \text { seizures/week } \\
\text { - daily seizures }\end{array}$ & $\begin{array}{c}4 \\
9 \\
24 \\
20 \\
13\end{array}$ & $\begin{array}{c}5.71 \pm- \\
12.86 \pm 4.00 \\
34.29 \pm 5.68 \\
28.57 \pm 5.40 \\
18.57 \pm 4.65\end{array}$ & $\begin{array}{l}11 \\
30 \\
18 \\
5 \\
6\end{array}$ & $\begin{array}{c}15.71 \pm 4.35 \\
42.86 \pm 5.91 \\
25.71 \pm 5.22 \\
7.14 \pm 3.08 \\
8.57 \pm 3.35\end{array}$ & $\chi^{2}=27.01$ & $<0.001$ & -0.40 \\
\hline $\begin{array}{l}\text { Seizure clusters and/or epileptic status } \\
\text {-no } \\
\text {-yes }\end{array}$ & $\begin{array}{l}35 \\
35\end{array}$ & $\begin{array}{l}50.00 \pm 5.98 \\
50.00 \pm 5.98\end{array}$ & $\begin{array}{c}66 \\
4\end{array}$ & $\begin{array}{c}94.29 \pm 2.77 \\
5.71 \pm-\end{array}$ & $\chi^{2}=34.16$ & $<0.001$ & -0.49 \\
\hline $\begin{array}{l}\text { Recent seizure frequency } \\
\text {-without seizures } \\
-1 / \text { several years } \\
-1-11 \text { seizures/year } \\
-1-3 \text { seizures/month } \\
\text {-1-6 seizures/week } \\
\text {-daily seizures }\end{array}$ & $\begin{array}{c}- \\
2 \\
11 \\
21 \\
32 \\
4\end{array}$ & $\begin{array}{c}- \\
2.86 \pm- \\
15.71 \pm 4.35 \\
30.00 \pm 5.48 \\
45.71 \pm 5.95 \\
5.71 \pm-\end{array}$ & $\begin{array}{l}70 \\
- \\
- \\
- \\
- \\
-\end{array}$ & $\begin{array}{c}100.00 \\
- \\
- \\
- \\
- \\
-\end{array}$ & $Z=11.02$ & $<0.001$ & -0.93 \\
\hline $\begin{array}{l}\text { Last month seizure severity (LSSS) } \\
\text {-mild (1-20) } \\
\text {-moderate }(21-40) \\
\text {-severe (41-60) } \\
\text {-very severe (61-80) }\end{array}$ & $\begin{array}{c}8 \\
32 \\
18 \\
1\end{array}$ & $\begin{array}{c}13.56 \pm 2.14 \\
54.24 \pm 6.22 \\
30.51 \pm 4.31 \\
1.69 \pm-\end{array}$ & $\begin{array}{l}- \\
- \\
-\end{array}$ & $\begin{array}{l}- \\
- \\
-\end{array}$ & - & - & - \\
\hline $\begin{array}{l}\text { Type of epilepsy } \\
\text {-partial } \\
\text {-generalized } \\
\text {-undefined }\end{array}$ & $\begin{array}{c}53 \\
16 \\
1\end{array}$ & $\begin{array}{l}75.71 \pm 5.11 \\
22.86 \pm 5.03 \\
1.43 \pm-\end{array}$ & $\begin{array}{l}24 \\
46 \\
-\end{array}$ & $\begin{array}{l}34.29 \pm 5.67 \\
65.71 \pm 5.67 \\
-\end{array}$ & $\chi^{2}=26.44$ & $<0.001$ & +0.41 \\
\hline $\begin{array}{l}\text { Etiology of epilepsy } \\
\text {-idiopathic } \\
\text {-cryptogenic } \\
\text {-symptomatic }\end{array}$ & $\begin{array}{l}17 \\
25 \\
28\end{array}$ & $\begin{array}{l}24.29 \pm 5.13 \\
35.71 \pm 5.73 \\
40.00 \pm 5.86\end{array}$ & $\begin{array}{l}30 \\
19 \\
21\end{array}$ & $\begin{array}{l}42.86 \pm 5.91 \\
27.14 \pm 5.31 \\
30.00 \pm 5.48\end{array}$ & $\chi^{2}=5.41$ & $>0.05$ & - \\
\hline $\begin{array}{l}\text { Recent therapy with AED } \\
\text {-monotherapy } \\
\text {-poly therapy }\end{array}$ & $\begin{array}{c}7 \\
63\end{array}$ & $\begin{array}{l}10.00 \pm 3.59 \\
90.00 \pm 3.59\end{array}$ & $\begin{array}{c}61 \\
9\end{array}$ & $\begin{array}{l}87.14 \pm 4.00 \\
12.86 \pm 4.00\end{array}$ & $\chi^{2}=83.38$ & $<0.001$ & -0.77 \\
\hline $\begin{array}{l}\text { Seizure reduction with the first AED } \\
-100 \% \\
->50 \% \\
-50 \% \\
-<50 \% \\
\text {-without reduction }\end{array}$ & $\begin{array}{l}5 \\
8 \\
4 \\
23 \\
30\end{array}$ & $\begin{array}{c}7.14 \pm 3.08 \\
11.43 \pm 3.80 \\
5.71 \pm- \\
32.86 \pm 5.61 \\
42.86 \pm 5.91\end{array}$ & $\begin{array}{c}44 \\
10 \\
- \\
10 \\
6\end{array}$ & $\begin{array}{c}62.86 \pm 5.77 \\
14.29 \pm 4.18 \\
- \\
14.29 \pm 4.18 \\
8.57 \pm 3.35\end{array}$ & $\chi^{2}=56.38$ & $<0.001$ & -0.60 \\
\hline $\begin{array}{l}\text { Focal neurological signs } \\
\text {-no } \\
\text {-yes }\end{array}$ & $\begin{array}{c}62 \\
8\end{array}$ & $\begin{array}{l}88.57 \pm 3.80 \\
11.43 \pm 3.80\end{array}$ & $\begin{array}{c}66 \\
4\end{array}$ & $\begin{array}{c}94.29 \pm 2.77 \\
5.71 \pm-\end{array}$ & $\chi^{2}=1.46$ & $>0.05$ & - \\
\hline
\end{tabular}

Regarding the heredity, a significant difference between the patients with RE and PSE has been proven - in 8 (11.43\%) of the participants with RE the disease was inherited. There is no consensus in scientific literature about the predictive role of heredity for intractability [12]. Few investigators have accepted heredity as a predictor of RE [1,8]. According to our study results heredity is associated with a more frequent intractability.
Polymorphic seizures have been registered more frequently in patients with RE - in 37 (52.86\%) of them. Some types of seizures (complex partial, tonic, atonic, myoclonic, atypical absences, infantile spasms) have been determined in scientific literature as refractory to the prescribed treatment and typical of malignant epilepsies, but there is no consensus if they are a preidictor of epilepsy intractability [12,16,22,30]. Lots of investigators 
have supported the statement, which was not confirmed by our study results, about the predictive role of the polymorphic seizures $[6,8,9,19,21,23]$. The conclusion that polymorphic seizures are frequent in patients with RE, but not a predictor of intractability, has been drawn.

Febrile seizures were found as more frequent in the participants with RE - in 18 (25.71\%) of them. There is no consensus in scientific literature about the predictive role of febnrile seizures for intractability. Hitiris (2007), McIntyre et al. (2006), Starreveld and Guberman (2006), and Tripathi et al. (2011) have demonstrated a higher frequency of febrile seizures in cases with RE [1,4,6,29]. Farrell et al. (2006) have supported the conclusion that these seizures cannot be defined as predictors of RE [16]. Naidenov (2007) has not proven a correlation between febrile seizures and intractability in his study with children [7]. According to our study results febrile seizures could be accepted as a predictor of intractability.

With regards to trigger factors, a significant difference between patients with RE and PSE has not been found. The conclusion that trigger factors are neither typical of RE, nor a predictor of intractability, has been drawn. Few investigators have associated the development of intractability with constant trigger factors or have described a high frequency (in 62\%) especially of the factors fever, sleep deprivation, and menstruation in patients with RE [8,31].

A higher initial seizure frequency has been registered in the patients with RE opposed to the patients with PSE daily seizures in 13 (18.57\%), 1-6 seizures/week - in 20 (28.57\%), 1-3/month - in 24 (34.29\%) of the participants with RE. A number of scientists have confirmed a much higher (up to 8 times) risk for the development of a RE in cases with a high initial seizure frequency and duration [32]. They have also pointed out the importance of the number of seizures and the duration of the period of time before the start of treatment [6,10,11,15,16,19,21,23,27,28,29]. Hitiris et al. (2007) have demonstrated a 2 times higher risk of a RE in cases with 10 seizures before the specific treatment starts [1]. Ramos-Lizana et al. (2009) have proven a higher risk for $\mathrm{RE}$ in cases with a combination of an early epilepsy onset and a high initial seizure frequency: $38 \%$ in patients with epilepsy onset earlier than 1 year of age and more than 1 seizure during the first 6 months from the diagnosis, 9\% in patients with epilepsy onset earlier than 1 year of age and $0-1$ seizure during the first 6 months from the diagnosis, $22 \%$ in patients with epilepsy onset at 1 year of age or above and more than 1 seizure during the first 6 months from the diagnosis, $3 \%$ in patients with epilepsy onset at 1 year of age or above and $0-1$ seizure during the first 6 months from the diagnosis [5]. The high initial seizure frequency has been accepted as a typical clinical finding and a predictor of RE.

The clusters of seizures and/or epileptic status are much more frequent in the patients with RE (in 50\%) and very typical of them. Epileptic status (especially the neonatal and the acute symptomatic status) and more rarely the seizure clusters have been determined as significant predictors of RE in scientific literature [3,4,9,16,17,22, 31,33]. According to our results, these clinical findings are typical of RE and intractability predictors.

The patients with RE have a much higher recent seizure frequency opposed to the patients with PSE - daily seizures in 4 (5.71\%), 1-6 seizures/week - in 32 (45.71\%), 1-3 seizures/month - in 21 (30\%) of the participants with RE. Data in support of the statement that the persistence of a high seizure frequency ( $>1$ seizure/month) is an important characteristic of the RE, have been found in scientific literature $[4,6,9,33,34]$. It has been accepted that high recent seizure frequency is typical of RE, but not a predictor of intractability.

Having evaluated the seizure severity, severe seizures were found in 18 (30.51\%) participants, moderate - in 32 (54.24\%), and mild - in 8 (13.56\%). Data about the typical seizure severity in patients with RE were not found in scientific literature. With regards to the severity, moderate seizures were accepted as more frequent in patients with RE. The predictive role for intractability of this variable has not been proven.

Partial epilepsy was demonstrated to be more frequent in the patients with RE - in 53 (75.71\%) compared to the patients with PSE - in 24 (34.29\%). These results are in conformity with the data from some studies $[2,12,19]$. It has been accepted that partial epilepsy is associated with a more frequent development of RE.

Regarding the etiology, a significant difference between the patients with RE and PSE has not been proven. However, the symptomatic etiology is more frequent in the group with RE - in 28 (40\%) cases. There is a concencus in the scientific literature about the high frequency of the symptomatic etiology in the first place and of the cryptogenic etiology in the second place in patients with RE [2,4,6,7,9,11,12,15,16,19,22,23,27,28, 30,35,36,37]. De Saint-Martin and Hirsch (2004) have determined the risk for RE development depending on the etiology and the type of epileptic syndrome - increased (34.6\%) in cases with a generalized symptomatic or a cryptogenic syndrome, moderate - in patients with a partial symptomatic or a cryptogenic (10.6\%) and an unclassified syndrome (10.4\%), low - in patients with an idiopathic syndrome (2.7\%) [15]. According to Sillanpää and Schmidt (2009) the symptomatic etiology is a predictor of a higher seizure frequency and a 9 times higher mortality [32]. The conclusion that the symptomatic etiology is more frequent in patients with RE, but not a predictor of intractability, has been drawn.

Approximately $90 \%$ of the patients with RE have been treated with poly therapy recently, which is much more frequent than the poly therapy treatment in the participants with PSE. Rasheva et al. (2003) have defined the treatment with a lower number of AED as a favorable predictor of a seizure control achievement [33]. Therefore the AED poly therapy is very typical of RE and one of the most significant unfavorable seizure control predictor.

A much greater number of ineffective AED $(\geq 4)$ has been found in patients with RE compared to those with PSE. Rasheva et al. (2004), Callaghan et al. (2007), and Tripathi et al. (2011) have defined the great number of ineffective AED as an unfavorable predictor of the seizure control $[3,29,33]$. The great number of prescribed ineffective AED has been accepted as a typical characteristic and one of the most significant predictors of epilepsy intractability.

The seizure reduction with the first AED was much poorer in the patients with RE compared to that of the patients with PSE - there was no reduction in 30 (42.86\%), and in $23(32.86 \%)$ the reduction was not significant. A 
great number of scientists have accepted that this finding is of primary importance for the prediction of RE. The results of several studies have demonstrared that the probability of seizure control is reduced 4-5 times after an ineffective first AED and becomes minimal (1-3\%) after an ineffective second AED [2,10,13,15,19,23,24,25]. The poor or lacking seizure reduction with the first AED has been accepted as a typical characteristic of RE and a predictor of intractability.

Regarding the focal neurological deficits, no significant difference between the patients with RE and those with PSE was found. The presence of focal neurological deficits was not accepted as typical or necessarily associated with intractability. Our conclusion does not support the data in literature about frequent focal neurological deficits in patients with RE [9,16,29,30,31, 34,38].

Poly therapy, early epilepsy onset, and great number $(\geq$ 4) of ineffective AED were the clinical findings with proven significance on multivariate analysis. They form a model with a high predictive value (88\%) for RE. Our results do not entirely support the data from the study of Tripathi et al. (2011) who have proven on multivariate analysis that significant intractability predictors are radiological evidence of structural cerebral abnormality, non-response to first AED, delayed milestones, high initial seizure frequency of more than one per month, partial seizure type, febrile seizures and age of onset before fourteen years [29].

\section{Limitations}

The first limitation of our study is the exclusion of patients older than 65 years, having cognitive impairment, progressive neurological disease, and those with simple or complex partial seizures in the last 4 hours or generalized tonic-clonic seizures in the last 24 hours with the purpose of an adequate collection of information and completion of the LSSS. The participation of no other patients but only those having access to the University Clinic of Neurology, who usually attended it for a regular examination or in cases of unsatisfactory seizure control or adverse events from treatment, is also a limitation. However, these limitations do not necessarily devalue the results from the first Bulgarian study on predictors and typical clinical findings of RE. Future studies including results from EEGs, CT scans, MRI are forthcoming. Besides, further investigations of patients having a variety of demographic, clinical, and social characteristics are needed.

In conclusion the most significant predictors of $\mathrm{RE}$ are poly therapy, childhood onset, and great number of ineffective AED. They form a model with a high predictive value which can be used for the assessment of $\mathrm{RE}$ risk. Other predictors and typical clinical findings of RE are: high initial seizure frequency, heredity for epilepsy, febrile seizures, partial epilepsy, low or lacking seizure reduction with the first AED, and clusters of seizures and/or epileptic status in the disease course. Frequent clinical findings without being predictors are: moderate seizure severity, high seizure frequency despite the prescribed treatment, polymorphic seizures. Etiology, seizure trigger factors, seizure type, and focal neurological signs are not typical of RE. Our findings may be very useful in medical practice. The knowledge about the typical clinical findings and predictors of RE is essential for the early diagnosis, adequate treatment, and prevention of its negative impact on all aspects of the quality of life.

\section{References}

[1] Hitiris N, Mohanraj R, Norrie J, Sills GJ, Brodie MJ. Predictors of pharmaco resistant epilepsy. Epilepsy Res. 2007. 75 (2-3): 192-6.

[2] Panov G. Comparative clinical, neuro-physiological and psychiatric assessment of patients with refractory and wellcontrolled epileptic seizures [thesis]. Pleven: Medical University, 2004.

[3] Callaghan BC, Arnaud K, Hesdoffer D, Hauser WA, French JA. Likelihood of seizure remission in an adult population with refractory epilepsy. Ann Neurol. 2007. 62 (4): 382-9.

[4] Mc Intyre D, Gilby K. Parahippocampal networks, intractability and the chronic epilepsy of kindling. Adv Neurol. 2006. 97: 77-83.

[5] Raffo E. Critères de pharmaco-résistance d'une épilepsie: les critères du neuropédiatre. Rev Neurol (Paris). 2004. 160 Spec №1: 5S48-52.

[6] Starreveld E, Guberman A. The spectrum of intractable epilepsy: a proposed scale. Adv Neurol. 2006. 97: 493-6.

[7] Naidenov A. Risk factors for the development of pharmaco resistant epilepsy in childhood. Epilepsy today. 2007. 1: 63-7.

[8] Cekov St. Epilepsy. Main characteristics, diagnostic, and therapeutic principles. Varna: Zograff. 2003: 327-9.

[9] Altunbaşak S, Herguner O, Regik Burgut H. Risk factors predicting refractoriness in epileptic children with partial seizures. J Child Neurol. 2007. 22 (2): 195-9.

[10] Andrade D, Zumsteng D, Sutula T, Wennberg R. Clinical aspects of temporal/limbic epilepsy and their relationship to intractability. Adv Neurol. 2006. 97: 39-44.

[11] Berg AT, Shinnar S, Levy SR, Testa FM, Smith-Rapport S, Beckerman B. Early development of intractable epilepsy in children: a prospective study. Neurology. 2001. 56 (11): 1445-52.

[12] Bordet R. Epilepsies partielles pharmacoresistantes: les critères du pharmacologue. Rev Neurol (Paris). 2004. 160 Spec №1: S36-42.

[13] Brodie MJ. Diagnosing and predicting refractory epilepsy. Acta Neurol Scand Suppl. 2005. 181: 36-9.

[14] Casetta I, Granieri E, Monetti VC, et al. Early predictors of intractability in childhood epilepsy: a community-based case control study in Copparo, Italy. Acta Neurol Scand. 1999. 99 (6): 329-33.

[15] De Saint-Martin A, Hirsch E. Les épilepsies partielles pharmacorésistantes. Quels sont les critères de pharnacorésistance pour le neuropédiatre? Rev Neurol (Paris). 2004. 160 Spec № 1: 5S43-7.

[16] Farrell K, Wirrel E, Whiting S. The definition and prediction of intractable epilepsy in children. Adv Neurol. 2006. 97: 435-42.

[17] French JA. Refractory epilepsy: clinical overview. Epilepsia. 2007. 48 (Suppl 1): 3-7.

[18] Gelisse P, Crespel A. Critères de gravité des épilepsies partielles pharmacorésistantes chez l'adulte. Rev Neurol (Paris). 2004. 160 Spec №1: 5S71-9.

[19] Jallon P. Epidemiology of drug-resistant epilepsy. Rev Neurol (Paris). 2004. 160 Spec №1: 5S22-30.

[20] Kwan P, Sander JW. The natural history of epilepsy: an epidemiological view. J Neurol Neurosurg Psychiatry. 2004. 75 (10): 1376-81.

[21] Silfevnius H. Cost and cost-effectiveness of epilepsy surgery. Epilepsia. 1999. 40 (Suppl 8): 32-9.

[22] Ko TS, Holmes GL. EEG and clinical predictors of medically intractable childhood epilepsy. Clin Neurophysiol. 1999. 110 (7): 1245-51.

[23] Panov G. Refractory epilepsy. Bulgarian Neurology. 2003. 3 (2): 98-101.

[24] Mohanraj R, Brodie MJ. Diagnosing refractory epilepsy: responses to sequential treatment schedules. Eur J Neurol. 2006. 13 (3): 277-82.

[25] Perucca E. Pharmacoresistance in epilepsy: how should it be defined? CNS drugs. 1998. 10: 171-9. 
[26] Sander JW. The prognosis of epilepsy. Outcome 2005. The National Society of epilepsy. E-epilepsy Library of articles: 32934.

[27] Chengyun D, Guominq L, Elia M, Catania MV, Qunyuan X. Expression of multidrug resistance type 1 gene (MDR1) Pglycoprotein in intractable epilepsy with different aetiologies: a double-labelling and electron microscopy study. Neurol Sci. 2006. 27 (4): 245-51.

[28] Del Campo J. Neocortical epilepsies: aspects distinguishing intractable from benign neocortical epilepsies. Adv Neurol. 2006. 97: 105-116.

[29] Tripathi M, Padhy UP, Vibha D, et al. Predictors of refractory epilepsy in north India: a case-control study. Seizure. 2011. 20 (10): 779-83.

[30] Chabolla D. Medically refractory seizures. Jacksonville Medicine 2000; dcms-footer. htm: 1-12.

[31] Fang PC, Chen YJ, Lee IC. Seizure precipitants in children with intractable epilepsy. Brain Dev. 2008. 30 (8): 527-32.

[32] Sillanpää M, Schmidt D. Early seizure frequency and aetiology predict long-term medical outcome in childhood-onset epilepsy. Brain. 2009. 132 (Pt 4): 989-98.
[33] Rasheva M, Milanova M, Radeva M, Atanasova D. Assessment of new AEDs as add-on therapy in patients with resistant partial epilepsies. Bulgarian Neurology. 2004.4 (4): 173-8.

[34] Genton P. Définition de la pharmacorésistance: le point de vue de l’épileptologue. Rev Neurol (Paris). 2004. 160 Spec №1: 5S53-60.

[35] Holtkamp M, Othman J, Buchheim K, Meierkord H. Predictors and prognosis of refractory status epilepticus treated in a neurological intensive care unit. J Neurol Neurosurg Psychiatry. 2005. 76: 534-9.

[36] Hui AC, Wong A, Wong HC, Man BL, Au-Yeung KM, Wong KS. Refractory epilepsy in a Chinese population. Clin Neurol Neurosurg. 2007. 109 (8): 672-5.

[37] Reynolds E. Treating refractory epilepsy in adults. BMJ. 2006. 332 (7541): 562-3.

[38] Sillanpää M, Haataja L, Shinnar S. Perceived impact of childhood onset epilepsy on quality of life as an adult. Epilepsia. 2004. 45 (8): 971-7. 